\title{
Comparação entre a relação PCR/albumina e 0 índice prognóstico inflamatório nutricional (IPIN)
}

\author{
Comparison of $P C R /$ albumin ratio with prognostic inflammatory nutritional index (PINI)
}

\author{
Camila Renata Corrêa \\ Aparecida Yooko Outa Angeleli ${ }^{2}$ \\ Nádia dos Reis Camargo ${ }^{3}$ \\ Luciano Barbosa ${ }^{4}$ \\ Roberto Carlos Burini ${ }^{5}$
}

\section{unitermos resumo}

Paciente crítico

Proteínas de fase aguda

Índice de estresse

inflamatório

Marcadores nutricionais
Objetivo: Simplificar o cálculo do índice prognóstico inflamatório nutricional (IPIN) empregando número menor de variáveis com conseqüente redução do custo da análise. Materiais e métodos: Foram estudados 54 pacientes e 12 indivíduos-controle com $48 \pm 20$ (média \pm dp) anos de idade. As principais patologias dos pacientes eram: doença arterial periférica (22), pênfigo foliáceo (7), doença inflamatória intestinal (7), trauma (6) e pós-operatório de ortognatia (3). Foram obtidas amostras de sangue periférico, colhidas em jejum para dosagens de proteínas positivas (+) e negativas (-) de fase aguda (PFA) pelo método nefelométrico. Proteína $C$ reativa (PCR), $\alpha$-1-glicoproteína-ácida $(\alpha-1-G A), \alpha$-1-antitripsina $(\alpha-1-A T)$ e ceruloplasmina (CER) foram as PFA+ e albumina (Alb), transtiretina (TTR), transferrina (TF) e proteína ligadora do retinol (RBP) foram as representantes das PFA-. Esses valores foram analisados quanto à associação de correlação isolada ou associadamente na fórmula do índice prognóstico inflamatório e nutricional (IPIN = PCR $+\alpha-1-$ GA / Alb + TTR). De acordo com o índice prognóstico inflamatório e nutricional, os pacientes foram classificados em grupo-controle (G1); pacientes sem infecção/inflamação (IPIN < 1, G2) ou com risco de inflamação/infecção (IPIN > 1, G3). Em seguida os pacientes do G3 foram subdivididos em baixo risco (G3A, $n=16)$; médio risco ( $G 3 B, n=10)$; alto risco $(G 3 C, n=6)$ e com risco de morte $(\mathrm{G} 3 \mathrm{D}, n=11)$. Os resultados foram correlacionados entre si (teste de Spearman) ou submetidos às comparações entre grupos (teste de Kruskall-Wallis). Resultados: Houve relação significativa entre as variáveis PCR $\times \alpha-1-\mathrm{GA}(r=0,49)$, Alb $\times \pi \mathrm{TR}(r=0,60), \operatorname{Alb} \times \operatorname{RBP}(r=0,58), \operatorname{Alb} \times \operatorname{TF}(r=0,39), \mathrm{TTR} \times \mathrm{RBP}$ $(r=0,56)$ e TTR $\times$ TF $(r=0,43)$ e as melhores relações encontradas entre PFA+ e PFA- foram: PCR $\times$ Alb $(r=-0,71), \mathrm{PCR} \times \mathrm{TTR}(r=-0,54), \mathrm{PCR} \times \mathrm{TF}(r=-0,39)$ e $\alpha-1-\mathrm{GA} \times$ Alb $(r=-0,35)$. Os valores do IPIN mostraram a diferenciação $G 3>(G 1=G 2)$ e $G 3>G 3$. Entre todas as proteínas dosadas apenas PCR, Alb e TTR discriminaram os grupos: sendo $G 3>(G 1=G 2)$ para PCR e $G 3<(G 1=G 2)$ para Alb e TTR. Apenas PCR, TTR e TF discriminaram a morbimortalidade com G3D > G3A (para PCR) e G3D < G3A (para TTR e TF). PCR/Alb e IPIN apresentaram concordância de valores para os riscos de complicações. Conclusão: Assim, conclui-se pela possibilidade de substituição do IPIN pela relação PCR/albumina, mais simples e de menor custo, mantendo-se o mesmo poder e sensibilidade para diagnóstico dos graus de risco de complicações. 


\section{Introdução}

Embora a resposta de fase aguda não seja específica, pode ser usada na prática clínica como parte do diagnóstico, tanto na avaliação da intensidade da atividade inflamatória como na discriminação de doenças inflamatórias das não-inflamatórias (29). Dessa forma, a detecção de um processo inflamatório agudo necessita de medida sensível e rápida de proteínas de fase aguda.

Para isso, Ingenbleek e Carpentier (13) propuseram o índice prognóstico inflamatório e nutricional (IPIN) composto pela combinação de duas proteínas positivas (proteína $C$ reativa e $\alpha$-1-glicoproteína ácida) e duas negativas (albumina e transtiretina).

A literatura traz alguns poucos trabalhos mostrando o uso do índice prognóstico inflamatório e nutricional para avaliar processos inflamatórios em várias situações $(5,6$, $12,15,26)$. A utilização de outras proteínas e mesmo o somatório de um número maior delas têm mostrado semelhanças com o IPIN em pacientes críticos $(26,28)$.

No geral, observa-se que esses índices são pouco utilizados na rotina hospitalar, talvez devido ao seu relativo alto custo (US\$15,00 /IPIN). Por isso uma possível simplificação neste índice poderia reduzir seu custo e torná-lo instrumento de uso freqüente na rotina hospitalar, auxiliando o diagnóstico inflamatório-nutricional e dimensionando o risco dos pacientes graves. Assim, o objetivo do trabalho foi simplificar o cálculo do IPIN empregando número menor de variáveis, com conseqüente redução do custo de análise.

\section{Casuística e métodos}

Foi realizado estudo retrospectivo envolvendo 66 indivíduos, 12 sadios e 54 portadores de diferentes doenças metabólicas, sendo 44 masculinos e 22 femininos, com média de idade de $48 \pm 20$ anos. Como fonte de material foram analisados dados de exames laboratoriais obtidos dos arquivos de pacientes atendidos pelo Centro de Metabolismo e Nutrição (CeMeNutri) da Faculdade de Medicina da Unesp, Botucatu (SP), no período de 1994 a 1998. Os indivíduos foram distribuídos pela gravidade inflamatória da doença, de acordo com a classificação de Ingenbleek e Carpentier (13), em: grupo 1 (G1), controle, formado por 12 indivíduos saudáveis ( $28,6 \pm 11,9$ anos, média \pm dp); grupo 2 (G2), com 11 pacientes (38,9 \pm 16,5 anos) sem risco de morbidade; e grupo 3 (G3), constituído por 43 pacientes $(54,3 \pm 16,8$ anos) com vários graus de morbimortalidade, subagrupados em 16 pacientes com baixo risco (G3A), dez pacientes com risco médio (G3B), seis com alto risco (G3C) e 11 pacientes com risco de morte (G3D).

Estes dois grupos ( $\mathrm{G} 2$ e G3) foram compostos por pacientes com doenças arteriais periféricas, pênfigo foliáceo, doença inflamatória intestinal, politrauma e pacientes póscirúrgicos (Tabela 1).

Tanto as proteínas positivas de fase aguda (PFA+) proteína $C$ reativa $(P C R), \alpha-1$-glicoproteína ácida $(\alpha-1-G A)$, ceruloplasmina (CER), $\alpha-1$-antitripsina ( $\alpha-1$-AT) - como as proteínas negativas (PFA-) - proteína ligadora do retinol (RBP), transferrina (TF) e transtiretina (TTR) - foram determinadas pelo método nefelométrico após reação com anticorpo específico (Diagnóstica São Paulo Produtos e Equipamentos para Laboratório Ltda., São Paulo-SP; kits e nefelômetro Behring). A albumina (Alb) foi determinada por método automatizado (Immunoassay Produtos Diagnósticos Ltda., Campinas-SP; auto-analisador Technicon Mod. RA-XT), empregando-se verde de bromocresol como reagente de cor (Diagnóstico da Saúde - Distribuidor Bayer Ribeirão Preto-SP; kits da Wiener).

$A$ avaliação de atividade inflamatória foi definida pelos valores do índice prognóstico inflamatório nutricional, segundo critério de Ingenbleek e Carpentier (13). O IPIN foi calculado a partir dos valores da proteína $C$ reativa, $\alpha$-1-glicoproteína ácida ( $\alpha$-1-GA), transtiretina e albumina, segundo a fórmula:

$$
\text { IPIN }=\frac{\alpha-1-G A(m g / l)+P C R(m g / l)}{\text { Alb }(g / l)+\text { TTR }(m g / l)}
$$

E a classificação dos pacientes pelos riscos de complicações, pelos valores:

- $>30$ - Paciente com risco de morte

- 21-31 - Paciente com alto risco de complicações

- 11-20 - Paciente com médio risco de complicações

- 1-10 - Paciente com baixo risco de complicações

- $\quad$ < 1 - Paciente sem infecção/inflamação

A comparação entre grupos foi feita pelo teste de Kruskal-Wallis, a associação entre as variáveis foi feita pela correlação de Spearman e, para estabelecer a classificação da relação PCR/albumina, por riscos de complicações dos indivíduos, foi aplicada a equação de intervalo de confiança para média (25). 


\section{Tabela 1 Caracterização dos grupos (G2 e G3) quanto ao tipo e à freqüência ( $n$ ) das doenças}

\begin{tabular}{llc}
\hline Grupo & Doença & $n$ \\
2 & Doença inflamatória intestinal ativa & 4 \\
2 & Pós-operatório de cirurgia bucomaxilofacial & 3 \\
2 & Pênfigo foliáceo controlado & 3 \\
2 & Aterosclerose obliterante periférica descompensada de membro inferior direito & 1 \\
3 & Aterosclerose obliterante periférica descompensada de membros inferiores & 16 \\
3 & Politrauma com múltiplas fraturas de ossos longos & 5 \\
3 & Pênfigo foliáceo ativo & 4 \\
3 & Oclusão arterial aguda de membros inferiores & 4 \\
3 & Doença inflamatória intestinal ativa & 3 \\
3 & Doença de Buerger & 2 \\
3 & Erisipela de perna direita & 2 \\
3 & Insuficiência respiratória + infecção brônquica & 1 \\
3 & Tromboangite obliterante de perna e pé esquerdo & 1 \\
3 & Pós-operatório de amputação de reto & 1 \\
3 & Choque hipovolêmico & 1 \\
3 & Embolia pulmonar + insuficiência respiratória & 1 \\
3 & Doença pulmonar obstrutiva crônica com insuficiência respiratória & 1 \\
3 & Infarto agudo do miocárdio estável & 1
\end{tabular}

\section{Resultados}

Os resultados da proteína positiva $\alpha$-1-glicoproteína ácida ( $\alpha-1-G A)$ não apresentaram diferenças entre os grupos $(\mathrm{G} 1=\mathrm{G} 2=\mathrm{G} 3)$. O mesmo ocorreu para $\alpha-1$-antitripsina e ceruloplasmina nos grupos G2 e G3 (G2 = G3); enquanto que os valores da proteína $\mathrm{C}$ reativa mostraram diferenças estatísticas com G3 > (G1 = G2) (Tabela 2).

Entre as proteínas negativas de fase aguda, a albumina e a transtiretina apresentaram diferenciação estatística apenas no $\mathrm{G} 3 \mathrm{com}(\mathrm{G} 1=\mathrm{G} 2)>\mathrm{G} 3$ (Tabela 2).

A PCR apresentou diferença, com o baixo risco sendo menor que o subgrupo com risco de morte. Os demais subgrupos apresentaram valores intermediários.

A albumina não apresentou diferença entre os subgrupos de G3, enquanto que a transtiretina diferiu, estatisticamente, com baixo risco, sendo maior que o subgrupo com risco de morte. Já a transferrina apresentou diferença entre os subgrupos do $\mathrm{G} 3$, com baixo, médio e o alto risco, sendo maiores que o risco de morte (Tabela 3). Com relação ao grupo 2, não apresentou diferença em relação a algum grau do grupo 3. A RBP mostrou resultados semelhantes entre os pacientes com baixo risco, alto risco (Tabela 3) e os do grupo sem risco de morbidade.

Para as proteínas positivas de fase aguda, houve correlação positiva significativa $(p<0,05)$ somente para PCR $\times$ $\alpha-1$-GA e para as proteínas negativas Alb $\times$ RBP; Alb $\times$ TTR; Alb $\times$ TF; TTR $\times$ TF e TTR $\times$ RBP. Com o cruzamento entre as proteínas positivas e negativas, a correlação foi significativa para PCR $\times$ Alb; PCR $\times$ TTR; PCR $\times$ TF; $\alpha-1-G A \times A l b$; CER $\times$ TTR.

A seqüência de correlações significativas entre PFA+ $x$ PFA- obedeceu à seguinte ordem: PCR $\times$ Alb $(r=-0,71)$, seguida da PCR $\times$ TTR $(r=-0,54), \mathrm{PCR}+$ transferrina $(-0,39)$ e $\alpha-1-G A \times$ Alb $(r=-0,35)$ (Tabela 4).

Quando se correlacionaram os valores das proteínas positivas e negativas entre todos os pacientes dos subgrupos do grupo 3 , observou-se que a PCR correlacionou-se negativamente com a TTR $(r=-0,37, p<0,05)$, $\operatorname{TF}(r=-0,39, p<0,01)$ e Alb $(r=-0,41, p<0,01)$. Não houve correlação significativa da $\alpha-1-G A$ com estas três representantes das PFA-. 
Valores de mediana e respectivos valores mínimos e máximos das proteinas positivas e negativas de fase aguda dos indivíduos-controle, sem riscos de complicação e com risco de morbimortalidade

\begin{tabular}{|c|c|c|c|c|c|c|}
\hline \multirow{2}{*}{ PFA+ } & \multicolumn{3}{|c|}{ Grupo } & \multirow[b]{2}{*}{$\begin{array}{l}\text { Estatística } \\
\text { calculada }\end{array}$} & \multirow[b]{2}{*}{$\begin{array}{l}\text { Nivel de } \\
\text { significância }\end{array}$} & \multirow[b]{2}{*}{ Comentário } \\
\hline & $\begin{array}{c}\text { G1 } \\
\text { Mediana } \\
\text { (min - máx) }\end{array}$ & $\begin{array}{c}\text { G2 } \\
\text { Mediana } \\
\text { (min - máx) }\end{array}$ & $\begin{array}{c}\text { G3 } \\
\text { Mediana } \\
\text { (min - máx) }\end{array}$ & & & \\
\hline $\begin{array}{l}\text { PCR } \\
(\mathrm{mg} / \mathrm{l})\end{array}$ & $\begin{array}{c}1 \\
(1-1)\end{array}$ & $\begin{array}{c}5,4 \\
(4,3-9,5)\end{array}$ & $\begin{array}{c}44,8 \\
(7,1-162,4)\end{array}$ & $\mathrm{H}=45,7$ & $p<0,05$ & $G 3>(G 1=G 2)$ \\
\hline $\begin{array}{l}\text { CER } \\
(\mathrm{mg} / \mathrm{l})\end{array}$ & - & $\begin{array}{c}368 \\
(299-481)\end{array}$ & $\begin{array}{c}391 \\
(83-777)\end{array}$ & $\mathrm{H}=2,1$ & $p>0,05$ & $\mathrm{G} 2=\mathrm{G} 3$ \\
\hline $\begin{array}{l}\alpha-1-A G \\
(m g / l)\end{array}$ & $\begin{array}{c}723 \\
(604-1.187)\end{array}$ & $\begin{array}{c}1.143 \\
(676-1.729)\end{array}$ & $\begin{array}{c}1.363 \\
(735-2.394)\end{array}$ & $\mathrm{H}=25,7$ & $p>0,05$ & $\mathrm{G} 1=\mathrm{G} 2=\mathrm{G} 3$ \\
\hline $\begin{array}{l}\alpha-1-\mathrm{AT} \\
(\mathrm{mg} / \mathrm{l})\end{array}$ & - & $\begin{array}{c}2.459 \\
(334-4.050)\end{array}$ & $\begin{array}{c}3.042 \\
(1.250-4.860)\end{array}$ & $\mathrm{H}=0,21$ & $p>0,05$ & $\mathrm{G} 2=\mathrm{G} 3$ \\
\hline $\begin{array}{l}\text { Alb } \\
(\mathrm{g} / \mathrm{l})\end{array}$ & $\begin{array}{c}47,5 \\
(42-52)\end{array}$ & $\begin{array}{c}45 \\
(37-49)\end{array}$ & $\begin{array}{c}35 \\
(22-51)\end{array}$ & $\mathrm{H}=30,4$ & $p<0,05$ & $\mathrm{G} 3<(\mathrm{G} 1=\mathrm{G} 2)$ \\
\hline $\begin{array}{l}\text { TTR } \\
(\mathrm{mg} / \mathrm{l})\end{array}$ & $\begin{array}{c}322 \\
(231-394)\end{array}$ & $\begin{array}{c}254 \\
(117-386)\end{array}$ & $\begin{array}{c}159 \\
(39-419)\end{array}$ & $\mathrm{H}=21$ & $p<0,05$ & $\mathrm{G} 3<(\mathrm{G} 1=\mathrm{G} 2)$ \\
\hline
\end{tabular}

PFA+: proteína positiva de fase aguda; PCR: proteína C reativa; $\alpha$-1-AC: $\alpha$-1-glicoproteína ácida; Alb: albumina; TTR: transtiretina; CER: ceruloplasmina; $\alpha$-1-AT: $\alpha$-1-antitripsina; G1: grupo 1 (controle); G2: grupo 2 (sem risco de complicações na morbidade); G3: grupo 3 (com risco de morbimortalidade).

Tabela 3

Valores de mediana e respectivos valores minimos e máximos das proteínas positivas e negativas de fase aguda dos indivíduos com baixo, médio e alto risco de morbimortalidade

\begin{tabular}{|c|c|c|c|c|c|c|c|}
\hline \multirow[b]{2}{*}{ PFA+ } & \multicolumn{4}{|c|}{ Grupo } & \multirow[b]{2}{*}{$\begin{array}{l}\text { Estatística } \\
\text { calculada }\end{array}$} & \multirow[b]{2}{*}{$\begin{array}{l}\text { Nível de } \\
\text { significância }\end{array}$} & \multirow[b]{2}{*}{ Comentário } \\
\hline & $\begin{array}{c}\text { G3A } \\
\text { Mediana } \\
\text { (min - máx) }\end{array}$ & $\begin{array}{c}\text { G3B } \\
\text { Mediana } \\
\text { (min - máx) }\end{array}$ & $\begin{array}{c}\text { G3C } \\
\text { Mediana } \\
\text { (min - máx) }\end{array}$ & $\begin{array}{c}\text { G3D } \\
\text { Mediana } \\
\text { (min - máx) }\end{array}$ & & & \\
\hline $\begin{array}{l}\text { PCR } \\
(\mathrm{mg} / \mathrm{l})\end{array}$ & $\begin{array}{c}19,1 \\
(7,1-52,8)\end{array}$ & $\begin{array}{c}57,6 \\
(38,4-90,1)\end{array}$ & $\begin{array}{c}108,5 \\
(30-162,4)\end{array}$ & $\begin{array}{c}104,9 \\
(39,6-162,4)\end{array}$ & $H=59,2$ & $p<0,05$ & $G 3 A<G 3 D$ \\
\hline $\begin{array}{l}\text { CER } \\
(\mathrm{mg} / \mathrm{l})\end{array}$ & $\begin{array}{c}378 \\
(242-777)\end{array}$ & $\begin{array}{c}498 \\
(185-740)\end{array}$ & - & $\begin{array}{c}347 \\
(83-639)\end{array}$ & $\mathrm{H}=2,1$ & $p>0,05$ & $\mathrm{G} 3 \mathrm{~A}=\mathrm{G} 3 \mathrm{~B}=\mathrm{G} 3 \mathrm{D}$ \\
\hline $\begin{array}{l}\alpha-1-\mathrm{AT} \\
(\mathrm{mg} / \mathrm{l})\end{array}$ & $\begin{array}{c}2.910 \\
(2.778-3.911)\end{array}$ & - & $\begin{array}{c}2.760 \\
(1.250-4.860)\end{array}$ & - & $\mathrm{H}=0,21$ & $p>0,05$ & $\mathrm{G} 3 \mathrm{~A}=\mathrm{G} 3 \mathrm{C}$ \\
\hline $\begin{array}{l}\alpha-1-A G \\
(m g / l)\end{array}$ & $\begin{array}{c}1.300 \\
(735-2.176)\end{array}$ & $\begin{array}{c}1.615 \\
(801-2.392)\end{array}$ & $\begin{array}{c}1.007 \\
(901-1.820)\end{array}$ & $\begin{array}{c}1.253 \\
(951-2.187)\end{array}$ & $\mathrm{H}=29,3$ & $p>0,05$ & $\begin{aligned} G 3 A & =G 3 B= \\
G 3 C & =G 3 D\end{aligned}$ \\
\hline $\begin{array}{l}\text { Alb } \\
(\mathrm{g} / \mathrm{l})\end{array}$ & $\begin{array}{c}42 \\
(28-55)\end{array}$ & $\begin{array}{c}36 \\
(28-45)\end{array}$ & $\begin{array}{c}31 \\
(22-35)\end{array}$ & $\begin{array}{c}32 \\
(22-35)\end{array}$ & $\mathrm{H}=41$ & $p>0,05$ & $\begin{aligned} G 3 A & =G 3 B= \\
G 3 C & =G 3 D\end{aligned}$ \\
\hline $\begin{array}{l}\text { TTR } \\
(\mathrm{mg} / \mathrm{l})\end{array}$ & $\begin{array}{c}222 \\
(73,2-419)\end{array}$ & $\begin{array}{c}193 \\
(137-274)\end{array}$ & $\begin{array}{c}130 \\
(56-292)\end{array}$ & $\begin{array}{c}123 \\
(39-178)\end{array}$ & $\mathrm{H}=31,4$ & $p<0,05$ & $\mathrm{G} 3 \mathrm{~A}>\mathrm{G} 3 \mathrm{D}$ \\
\hline $\begin{array}{l}\mathrm{TF} \\
(\mathrm{mg} / \mathrm{l})\end{array}$ & $\begin{array}{c}2.605 \\
(1.485-3.467)\end{array}$ & $\begin{array}{c}2.226 \\
(1.816-3.276)\end{array}$ & $\begin{array}{c}1.144 \\
(1.144-2.670)\end{array}$ & $\begin{array}{c}1.435 \\
(663-2.231)\end{array}$ & $\mathrm{H}=14$ & $p<0,05$ & $\begin{aligned}(G 3 A & =G 3 B= \\
G 3 C) & >G 3 D\end{aligned}$ \\
\hline $\begin{array}{l}\mathrm{RBP} \\
(\mathrm{mg} / \mathrm{l})\end{array}$ & $\begin{array}{c}61 \\
(38-92)\end{array}$ & - & $\begin{array}{c}25 \\
(25-29)\end{array}$ & - & $\mathrm{H}=4,95$ & $p>0,05$ & $G 3 A=G 3 C$ \\
\hline
\end{tabular}

PFA+: proteína positiva de fase aguda; PCR: proteína C reativa; $\alpha$-1-AG: $\alpha$-1-glicoproteína ácida; Alb: albumina; TTR: transtiretina; CER: ceruloplasmina; $\alpha$-1-AT: 
Tabela 4 Associação linear (correlação de Spearman) entre os valores de proteinas de fase aguda

\begin{tabular}{lccccccc} 
& $\alpha-1-G A$ & $\alpha-1-A T$ & CER & Alb & TTR & TF & RBP \\
PCR & $0,49^{*}$ & 0,26 & $-0,01$ & $-0,71^{*}$ & $-0,54^{*}$ & $-0,39^{*}$ & $-0,44$ \\
$\alpha-1-G A$ & - & $-0,14$ & 0,20 & $-0,35^{*}$ & $-0,18$ & $-0,04$ & 0,13 \\
$\alpha-1-A T$ & & - & $-0,04$ & $-0,34$ & $-0,21$ & 0,04 & $-0,23$ \\
CER & & & - & 0,07 & $0,38^{*}$ & 0,33 & $-0,01$ \\
Alb & & & & - & $0,60^{*}$ & $0,39^{*}$ & $0,58^{*}$ \\
TTR & & & & & - & $0,43^{*}$ & $0,56^{*}$ \\
TF & & & & & & - & 0,23 \\
\hline
\end{tabular}

PCR: proteína C reativa; $\alpha-1$-GA: $\alpha$-1-glicoproteína ácida; $\alpha-1$-AT: $\alpha-1$-antitripsina; CER: ceruloplasmina; Alb: albumina; TTR: transtiretina; TF: transferrina; RBP: proteína ligadora do retinol; ${ }^{*} p<0,05$.

Baseando-se na correlação entre proteína $C$ reativa e albumina, propôs-se a relação PCR/Alb para substituição do IPIN. Calculados os valores da relação PCR/Alb para todos os grupos e, em seguida, realizada a correlação IPIN $\times$ PCR/Alb, observou-se índice significativo de $r=0,96$ $(p<0,0001)$. Ambas as fórmulas mostraram o mesmo comportamento com $(\mathrm{G} 1=\mathrm{G} 2)<\mathrm{G} 3$.

Quanto ao grupo com risco de morbimortalidade (G3), que contém os quatro graus de gravidade, a relação PCR/Alb também foi semelhante ao IPIN, com o subgrupo de baixo risco significativamente menor que o risco de morte (Figura). Assim, constituiu-se o quadro de equivalência dos resultados dos dois índices obtidos para cada um dos graus de complicações (Tabela 5).

\section{Discussão}

A casuística deste trabalho foi composta por indivíduos sadios e doentes, com predominância do sexo masculino (63\% dos casos). Entre as proteínas positivas de fase aguda estudadas, a proteína $C$ reativa foi a única a discriminar os grupos com $(\mathrm{G} 1=\mathrm{G} 2)<\mathrm{G} 3$.

Também no grupo 3, a PCR foi discriminante, tendo os pacientes com baixo risco de morbimortalidade valores menores que os pacientes com risco de morte. Com isso, pode-se destacar a PCR como proteína indicadora da gravidade da doença (20). Midha e Stratton (19) propuseram as dosagem desta proteína como teste laboratorial indicado para o paciente crítico.

A PCR é detectável cerca de seis horas após a lesão e tem seu pico em torno do segundo dia, com valores até 3 mil vezes sua concentração normal, dependendo do grau de inflamação.
Em dosagens diárias de PCR de pacientes de unidade de terapia intensiva (UTI) que apresentavam infecção, foi observado que essas medidas puderam monitorar a infecção e o sucesso do tratamento (31). Em nosso meio, a PCR conseguiu discriminar a melhor eficácia do tratamento da sulfassalazina, comparativamente aos ácidos graxos ômega 3 de óleo de peixe, em pacientes com retocolite ulcerativa inespecífica em atividade leve ou moderada (9).

A $\alpha$-1-GA começa a se elevar cerca de 12 a 42 horas após o estímulo. É uma proteína que aumenta até quatro vezes seu valor durante a inflamação aguda, a doença inflamatória intestinal e o câncer. Devido ao seu aparecimento mais lento na circulação, pode ser utilizada como um indicador de cronicidade (27) da doença. Isto poderia explicar, no estudo, a falta de diferença entre os grupos $(G 1=G 2=G 3)$.

Albumina e transtiretina são proteínas negativas de fase aguda, que tendem a diminuir suas concentrações séricas diante de um processo inflamatório. Isto ocorre devido à inibição da sua síntese pelas citocinas pró-inflamatórias $(2,22)$ e ao aumento da permeabilidade vascular, com conseqüente saída para os espaços extravasculares (7).

Em pacientes com choque séptico, a saída da albumina para o espaço extravascular pode ter um aumento da ordem de $300 \%$, sendo que, em pacientes pós-cirúrgicos, o escape ocorre em 7 horas após o processo e chega a atingir $100 \%$. Assim, a taxa de escape da albumina é de $5 \% /$ hora, ou seja, dez vezes superior à sua taxa de síntese (11).

De modo semelhante, também a transtiretina tem sua concentração sérica diminuída diante do processo infla- 


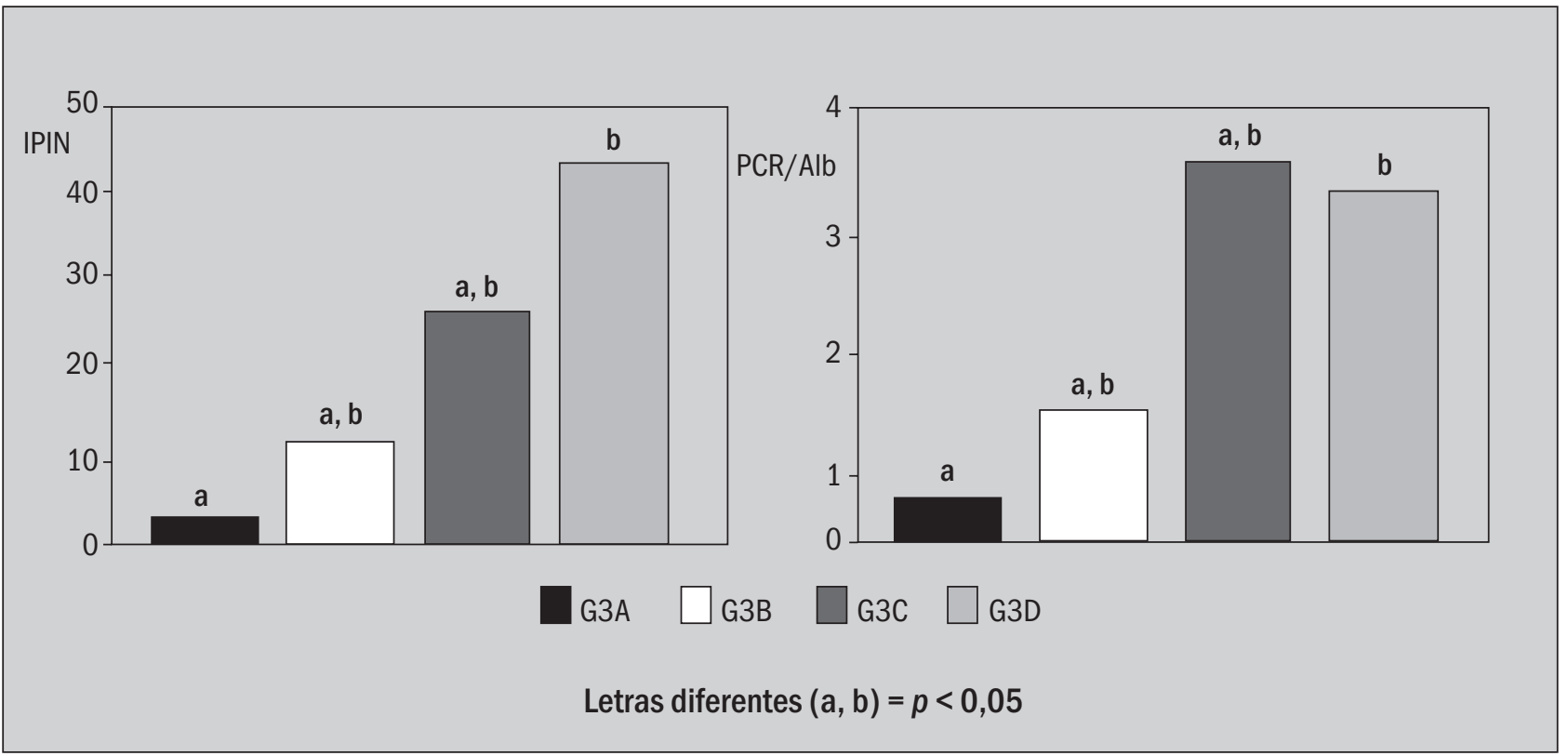

Figura - Valores da mediana dos índices prognóstico inflamatório e nutricional (IPIN) e proteína C reativa/albumina (PCR/Alb) dos pacientes com vários graus de risco de morbimortalidade ( $\mathrm{G} 3 \mathrm{~A}=$ baixo risco; $\mathrm{G} 3 \mathrm{~B}=$ médio risco; $\mathrm{G} 3 \mathrm{C}=$ alto risco; $\mathrm{G} 3 \mathrm{D}=$ risco de morte)

Tabela 5 para os pacientes

\begin{tabular}{lcc}
\hline $\begin{array}{l}\text { Grau de risco } \\
\text { de complicações }\end{array}$ & IPIN & PCR/Alb \\
Sem risco & $<1$ & $<0,4$ \\
Baixo risco & $1-10$ & $0,4-1,2$ \\
Médio risco & $11-20$ & $1,2-2,0$ \\
Alto risco & $21-30$ & $>2,0$ \\
Risco de morte & $>30$ & \\
\hline
\end{tabular}

matório, devido ao aumento da permeabilidade vascular, uma das causas mais importantes desta redução (16).

Com relação aos resultados encontrados neste trabaIho, observamos que a albumina e a transtiretina discriminam os grupos com $(G 1=G 2)>G 3$. A justificativa deste comportamento seria o fato de os pacientes do grupo 3 apresentarem processos inflamatórios mais graves, apresentando maior escape vascular, assim como maior bloqueio de síntese dessas proteínas.

Em relação aos subgrupos do grupo 3, a transtiretina foi maior nos pacientes que tinham baixo risco de morbimortalidade, havendo uma concentração sérica menor nos pacientes com risco de morte, confirmando o raciocínio acima e a idéia de que esta proteína pode ser sinalizadora de gravidade do paciente crítico (4). De modo semelhante, houve diferença entre o baixo risco e o risco médio com relação ao risco de morte para os valores de transferrina.

A diminuição do ferro sérico nas situações em que o paciente apresenta anemia ferropriva, como é o caso de doentes com retocolite ulcerativa inespecífica, poderia ser um complicador na interpretação do resultado de transferrina, uma vez que o nível desta proteína neste tipo de anemia está elevado, sem que haja saturação dos sítios de ligação com o ferro (10).

Com base nesses fatos, a transtiretina pode ser um sinalizador negativo seguro da gravidade do paciente crítico; já a transferrina necessita de estudo mais específico para isolar as influências da infecção e dos níveis séricos de ferro dos pacientes (10).

A proteína ligadora do retinol e a transtiretina são proteínas que agem no transporte do retinol. Estas duas proteínas parecem ter o mesmo comportamento na resposta de fase aguda, com diminuição da síntese e aumento do escape extravascular (2). Com relação aos dados do presente trabalho, observamos comportamentos diferentes entre elas. Quando comparamos os subgrupos do grupo 3, a TTR apresentou diferença apenas entre 0 baixo risco, que foi maior que o risco de morte, enquanto que a RBP não mostrou diferença entre os subgrupos. Estas proteínas podem apresentar comportamento diferente na inflamação, dependendo do nível sérico de retinol $(21,23)$. 
Foi observado que o grupo-controle não difere do grupo sem risco de complicações, pois esses pacientes não tinham processo inflamatório grave. O grupo com risco de morbimortalidade seria o grupo diferente, pois possui um grau de inflamação mais grave.

Entretanto, quando comparamos os subgrupos do grupo 3 entre si, observamos que houve diferença apenas entre o baixo risco e o risco de morte, particularmente pelo aumento da PCR e pela queda da TTR, influenciadoras do cálculo do IPIN. Sendo assim, os pacientes que possuem baixo risco de morbimortalidade podem não estar com processo inflamatório tão grave, de modo que o IPIN seria discriminante apenas de processos inflamatórios graves.

Nos pacientes mais graves do grupo, a proteína $C$ reativa correlacionou-se negativamente com a albumina, a transtiretina e a transferrina. Sabe-se que a PCR é a proteína positiva da fase aguda de comprometimento mais indicativo da gravidade da doença inflamatória com ou sem presença de infecção. Seus níveis são proporcionais à área de lesão e, mesmo, à morbimortalidade dos pacientes $(14,28,30)$. Os níveis séricos de PCR guardam relação com a atividade de citocinas pró-inflamatórias (31). As citocinas pró-inflamatórias podem ser responsabilizadas também pela menor síntese de proteínas negativas da fase aguda (22). No presente trabalho, albumina, transferrina e transtiretina foram as proteínas que se correlacionaram, negativamente, de modo significativo com a PCR no grupo 3. A redução simultânea das três proteínas negativas guarda relação com a mortalidade dos pacientes críticos (20), embora elas constituam bons índices de gravidade também quando isoladas. No caso da transferrina, foi verificada, com a gravidade do trauma, uma diminuição na concentração sérica. Nas queimaduras, os níveis desta proteína apresentam relação com o balanço nitrogenado (3).

Talvez por ser proteína que permite dosagem mais fácil e rápida que as demais, a albumina está freqüentemente associada à gravidade do paciente, constituindo a hipoalbuminemia indicador prognóstico de pacientes cirúrgicos graves, pacientes de UTI, pacientes com doenças inflamatórias, ou trauma craniencefálico $(1,17)$. Nos pacientes geriátricos, a hipoalbuminemia $(<3,3 \mathrm{~g} / \mathrm{dl})$, na admissão hospitalar, pode ser utilizada como índice preditivo de mortalidade (8), enquanto que, em unidade de terapia intensiva, o uso de ventilação mecânica foi mais freqüente em pacientes hipoalbuminêmicos, superando em sensibilidade o Apache II $(18,24)$.
Portanto o determinante da significância da regressão passa a ser a proteína positiva em que ambas (PCR e $\alpha-1-G A$ ) têm suas sínteses induzidas por citocinas pró-inflamatórias, em ritmo mais rápido para a $\mathrm{PCR}$, a qual apresenta também clareamento mais rápido. Dessa forma fica evidente que a correlação negativa das proteínas negativas da fase aguda será mais significativa com a PCR, se avaliada nas primeiras 24 horas do trauma, juntamente com o Apache II, ou mais significativa, com a $\alpha-1-G A$, se avaliada de três a cinco dias após trauma.

Como foi verificado através da correlação de Spearman, as proteínas positivas de fase aguda PCR e $\alpha-1-G A$ são as únicas que se correlacionam positivamente. As duas já compõem o IPIN; com isso observamos que, entre as proteínas positivas, não foi possível uma substituição pela fórmula original.

Com relação às proteínas negativas, todas apresentaram uma boa correlação; sendo assim, a substituição da albumina ou da transtiretina pelas demais proteínas seria possível.

A relação PCR/Alb, como foi observado, pode ser uma alternativa para simplificação da fórmula original (IPIN), pois estas duas proteínas correlacionaram-se negativamente, tanto entre os pacientes mais graves (G3), como entre todos os indivíduos do estudo $(\mathrm{G} 1, \mathrm{G} 2, \mathrm{G} 3)$, tendo o mesmo comportamento que o IPIN $(\mathrm{G} 1=\mathrm{G} 2)<\mathrm{G} 3$.

A partir da quase coincidência $(r=0,96)$ entre os valores do IPIN e da relação PCR/Alb, propôs-se a equivalência de valores classificatórios dos graus de risco de complicações do estresse inflamatório.

Portanto, mediante simplificação, esse índice poderia ser mais utilizado devido à redução do custo e à facilidade da dosagem, já que a Alb e a PCR são exames realizados em serviços de rotina.

\section{Conclusão}

Com base nesta casuística, podemos concluir que a relação PCR/Alb pode substituir o IPIN, mantendo o mesmo poder e sensibilidade diagnóstica dos graus de risco de complicações.

\section{Agradecimentos}

Aos responsáveis clínicos pelos pacientes de doenças vasculares (professor dr. Francisco Humberto de Abreu Maffei, FMUNESP), doenças inflamatórias intestinais (prof. dr. Isaias Dichi, UEL), e UTI (dr. José Carlos Christovam), e às nutricionistas dra. Suely Barros de Almeida Peres (pacientes ortognáticos do HRLLP, USP) e Luciene de Souza Venâncio (pacientes vasculares do HC, FMUnesp). 


\section{Referências}

I. Bradley, J.A. et. al. Serum proteins levels in critically ill surgical patients. Intensive Care Med., 7: 291-95, 1981.

2. Calamita, Z. \& Burini, R.C. Fatores reguladores dos níveis plasmáticos de transtiretina e proteína ligadora do retinol. Rev. Bras. Pat. Clin., 29:| 48-53, 1993.

3. Carlson, D.E. et. al. Evaluation of serum visceral protein levels as indicators of nitrogen balance in thermally injured patients. J. Parenter. Enteral Nutr., 15:440-4, 1991.

4. Casati, A. et. al. Rapid turnover proteins in critically ill ICU patients. Negative acute phase proteins or nutritional indicators? Minerva Anestesiol., 64: 345-50, 1998.

5. Castagnola, E. et. al. Early efficacy of lipossomal amphotericin B in the treatment of visceral leishmaniasis. Trans. R. Soc. Trop. Med. Hyg., 90: 317-8, 1996.

6. Claxtron, B. The prognostic inflammatory and nutritional index in traumatized patients receiving enteral nutrition support. J. Parenter. Enteral Nutr., 16: 85-6, 1992.

7. Corrêa, C.R. \& Burini, R.C. Proteínas plasmáticas positivas à fase aguda. J. Bras. Patol.,36( I): 48-56, 2000.

8. D'Erasmo, E. et. al. Serum albumin level at admission : mortality and clinical outcome in geriatric patients. Am.J. Med. Sci., 3 । 4: 17-20, 1997.

9. Dichi, I. et. al. Comparison of w3 fatty acids and sulfasalazine in ulcerative colitis. Nutrition, 16: 87-90, 2000.

I0. Dichi, J. \& Burini, R. C. Metabolismo do cobre e da anemia. Rev. Bras. Nutr. Clin. , 6: |3-21,199|

I I. Fleck, A.; Colley, C.M. \& Myeres, M.A. Liver export proteins and trauma. Br. Med. Bull., 4 I (3): 265-73, 1985.

12. Gunel, E. et. al. Acute phase in children recovering from minor surgery. Pediatr. Surg. Int., 14:199-201, 1998.

13. Ingenbleek, Y., Carpentier,Y.A. A prognostic inflammatory and nutritional index scoring critically ill patients. Int. J. Vitam. Nutr. Res., 55: 91 - 101, 1985.

14. Kaplan, M.H. C-reactive protein: relation to disease and pathological significance. Ann. N. YorkAcad. Sci., 389:419-22, 1982.

15. Kudlackova, M. et. al. Acute phase proteins and prognostic inflammatory and nutritional index (PINI) in moderately burned children aged up to 3 years. Burns, 16: 53-6, 1990.

16. Malavé, l. et. al. Serum levels of thyroxine- binding prealbumin, C-reactive protein and interleikin-6 in protein- energy undernourished children and normal controls without or with associated clinical infectious. J. Trop. Pediatr., 44: 25662, 1998

17. Mc Clain, C. J. et. al.Serum and urine zinc response in headinjured patients. J. Neurosurg., 64: 224-30, 1986.

18. Mc Cluskey, A.N. et. al. The prognostic value of serial measurements of serum albumin concentration in patients admitted to an intensive care unit. Anaesthesia, 51:724-27, 1996.

19. Midha, N.K. \& Stratton, C.W. Laboratory tests in critical care. Crit. Care Clin., 14:15-34, 1998.

20. Owen, W.F. \& Lowrie, E.G. C-Reactive protein as an outcome predictor for maintenance hemodialysis patients. Kidney Int., 54: 627-36, 1998.
21. Pereira, P.C.M. Impacto nutricional da síndrome de imunodeficiência adquirida (SIDA). Botucatu, 1992. 107 p. Tese (Doutoramento em Clínica Médica, Área de Concentração: Metabolismo e Nutrição) - Faculdade de Medicina, Universidade Estadual Paulista.

22. Pereira, P.C.M. \& Burini, R.C. Reação metabólica à infecção no hospedeiro. Ver. Hosp. Clin. Fac. Med. S. Paulo, 47:I I I- 5, 1992.

23. Rosales, F.J. \& Ross, A.C. A low molar ratio of retinol binding protein to transthyretin indicates vitamin A deficiency during inflammation: studies in rats and posteriori analysis of vitamin A- supplemented children with measles. J. Nutr., I 28: 1681-7, 1998.

24. Sapijaszko, M.A.J. et. al. Nonrespiratory predictor of mechanical ventilation dependency in intensive care unit patients. Crit. Care Med., 24: 601- 7, 1996.

25. Siegel, S. Estatística não-paramétrica. São Paulo: McGraw-Hill Ltda, 1975.

26. Teixeira, U.A. Metabolismo protéico global e hormônios de pacientes politraumatizados (sem lesão craniencefálica) submetidos ao jejum e terapia nutricional enteral com e sem glicose hipertônica endovenosa. Botucatu, 1998. 107 p. Tese (Doutoramento em Clínica Médica, Área de Concentração: Metabolismo e Nutrição) - Faculdade de Medicina, Universidade Estadual Paulista.

27. Thompson, D., Milford-Ward, A. \& Whicher, J.T. The value of acute phase protein measurement in clinical practice. Ann. Clin. Biochem., 29: 123-31, 1992.

28. Tsuji, H. Diferenciação metabólica-hormonal de pacientes traumatizados, com e sem lesão craniencefálica, recebendo dieta enteral hiperprotéica-hiperenergética, suplementada ou não com glicose hipertônica endovenosa. Botucatu, 1995. 155 p. Tese (Doutoramento em Clínica Médica, Área de Concentração: Metabolismo e Nutrição) - Faculdade de Medicina, Universidade Estadual Paulista.

29.Van Leeuwen, M. A. \& Van Rijswijk, M.H. Acute phase proteins in the monitoring of inflammatory disorders. Baillieres Clin. Reumatol., 8: 531-52, 1994.

30. Wolbink, M.C.M.; Thys, L.G. \& Hack, E. Complement activation in patients with healthysepsis is in part mediated by $\mathrm{C}$ reactive protein. J. Infect. Dis., 1 77: 81-7, 1998.

31. Yentis, S.M.; Soni, M. \& Sheldon, J. C-reactive protein as an indicator of resolution of sepsis in the intensive care unit. Intensive Care Med., 21: 602-5, 1995.
Endereço para correspondência

Roberto Carlos Burini Departamento de Clínica Médica da Faculdade de Medicina da Unesp CEP 18618-970 - Botucatu-SP 